DOI: https://doi.org/10.24867/13CG08Kronic

\title{
PROCENA STANJA I ENERGETSKA SANACIJA PORODIČNE STAMBENE ZGRADE U PETROVARADINU
}

\section{ASSESSMENT OF CONDITION AND ENERGY RENOVATION OF FAMILY RESIDENTIAL BUILDING IN PETROVARADIN}

\author{
Jovana Kronić, Fakultet tehničkih nauka, Novi Sad
}

\begin{abstract}
Oblast - Građevinarstvo
Kratak sadržaj - Rad se sastoji iz teorijsko-istraživačkog i praktčnog dela. U istraživačkom delu obrađena je tema osnovnih uslova komfora, a zatim je detaljnije predstavljeno projektovanje $u$ skladu sa toplotnim zoniranjem. U praktičnom delu je urađena procena stanja jedne porodične stambene kuće u Petrovaradinu. Nakon toga izvršen je proračun energetske efikasnosti predmetnog objekta. Pomenuti proračun ponovljen je nakon predloženih mera sanacije, te je izvršeno upoređenje stanja pre $i$ posle sanacije - dobijeni energetski razred " $D$ " pre sanacije postao je razred " $C$ " za stanje saniranog objekta.
\end{abstract}

Ključne reči: Uslovi komfora, Toplotno zoniranje, Energetska efikasnost, Sanacija

\begin{abstract}
The paper consists of theoretical-research and practical work. In the research part, the topic of basic comfort conditions is treated, and then the design in accordance with thermal zoning is presented in more detail. In the practical part, an assessment of the condition of a family residential house in Petrovaradin was done. After that, the calculation of the energy efficiency of the building was performed. The mentioned calculation was repeated after the predicted rehabilitation measures, and a comparison of the condition before and after the rehabilitation was performed - the obtained energy class " $D$ " before the rehabilitation became class " $C$ " for the condition of the rehabilitated facility.
\end{abstract}

Keywords: Comfort conditions, Thermal zoning, Energy efficiency, Rehabilitation

\section{USLOVI KOMFORA}

\subsection{Osnovni uslovi}

Prema odredbama Pravilnika o energetskoj efikasnosti u zgradarstvu, propisuju se energetska svojstva i način proračuna toplotnih svojstava objekata visokogradnje, kao i energetski zahtevi. Uz ispunjenje energetske efikasnosti zgrade potrebno je zadovoljiti i sve uslove komfora: vazdušni, svetlosni, zvučni i toplotni.

Dužnost projektanta jeste da u sklopu tehničke dokumentacije jasno navede sve mere kao i tehnička

\section{NAPOMENA:}

Ovaj rad proistekao je iz master rada čiji mentor je bila dr Mirjana Malešev, red. prof. rešenja za postizanje projektovanih parametara komfora [3].

\subsection{Toplotno zoniranje}

Budući da toplotni komfor predstavlja psihološko stanje koje odgovara ugodnom osećaju toplotnih uslova u prostoru, odnosno, kojima je postignuta toplotna ravnoteža organizma, podrazumeva se da su objektivni parametri toplotnog komfora: temperatura vazduha, srednja temperatura zračenja površina, brzina kretanja vazduha i vlažnost vazduha. Dakle, termičko zoniranje zgrade obuhvata grupisanje pojedinih delova zgrade $u$ skladu sa njihovim potrebama za održavanjem određenih termičkih uslova [6].

Imajući na umu zabeležen porast potrošnje energije u stambenim zgradama (i kućama), u poslednje vreme naglašava se potreba za predlaganjem mera za poboljšanje energetske efikasnosti. Ono što privlači sve veću pažnju jeste planiranje u skladu sa mikroklimatskim uslovima lokacije, koje može dovesti do smanjenja potrošnje energije u objektima kroz pasivno korišćenje solarne energije. Takođe, energetska efikasnost se može postići i optimizacijom arhitektonsko - građevinskih parametara kao što su oblik zgrade, struktura njenog omotača i procenat staklenih površina, uz zadovoljenje toplotnog komfora korisnika prostora.

\subsection{Arhitektonsko - građevinske mere}

Arhitektonsko-građevinskim merama potrebno je sprečiti prekomeran prolaz toplote kroz fasadne i pregradne konstrukcije zgrade u toku zime i omogućiti akumuliranje toplote u zgradi. Na ovaj način moguće je uštedeti energiju potrebnu za grejanje zgrada u toku zime i sprečiti pregrevanje prostorija zgrade $\mathrm{u}$ toku leta. Ove mere podrazumevaju pravilno dimenzionisanje i oblikovanje zgrada, pomenuto toplotno zoniranje, veću toplotnu izolaciju fasadnih pregrada zgrade, ugradnju prozora sa najmanje trostrukim zastakljenjem koje odgovara pasivnom zahvatu sunčeve energije, veće ostakljenje južne fasadne površine, stalno regulisanje ventilacije zgrade, zaštitu toplotno izolacionih materijala od vlaženja, itd. [6].

Kao vodeća načela među pomenutim merama, može se istaći sledeće: što je bolja termička izolacija i zaptivenost prozora i vrata, a manji faktor oblika, potrebna snaga sistema za grejanje će biti manja (Slika 1). 
Tek pošto su iscrpljene sve arhitektonsko-građevinske mogućnosti za postizanje toplotnog komfora, opravdano je uvesti sisteme za grejanje, hlađenje i ventilaciju [3].

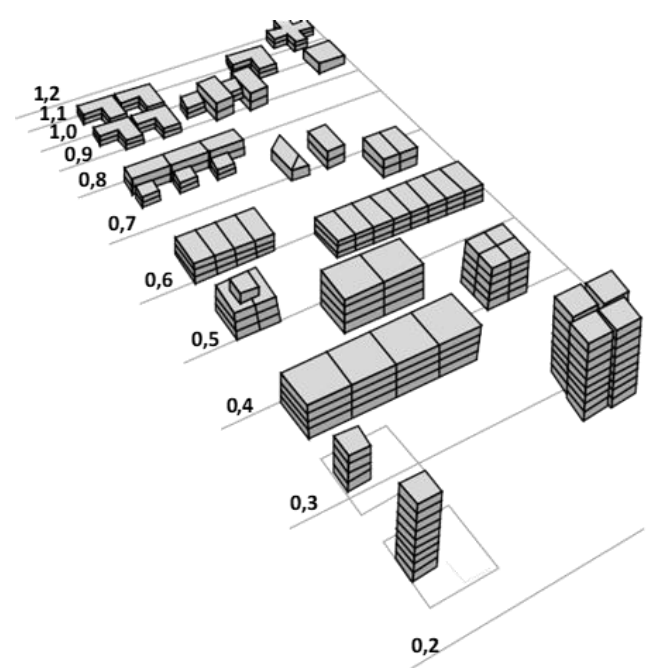

Slika 1. Faktori oblika različitih tipova zgrada [6]

\section{PROCENA STANJA OBJEKTA}

\subsection{Tehnički opis konstrukcije}

Predmet analize ovog rada jeste jedan stambeni objekat, porodična kuća, koja se nalazi u Novom Sadu, naselje Petrovaradin, u ulici Dinka Šimunovića broj 89. Reč je o objektu koji se sastoji iz podzemnog dela - garaže, prizemlja i sprata (slika 2).

Predmetni objekat pripada kategoriji zidanih objekata sa armirano betonskim horizontalnim i vertikalnim serklažima (na svim uglovima i mestima sučeljavanja zidova), i unutrašnjim horizontalnim dijafragmama tavanicama. Kuća je u osnovi dimenzija 13,0x10,0m. Svetla visina prizemlja iznosi $275 \mathrm{~cm}$, kao i sprata. Površina prizemlja je $89,59 \mathrm{~m}^{2}$, dok sprata iznosi $51,98 \mathrm{~m}^{2}$.

Konstrukcija je projektovana sa masivnim konstruktivnim zidovima potrebne debljine, pri čemu su upotrebljeni elementi za zidanje - giter blok i opeka. Na osnovu područja seizmičkog intenziteta, predviđeni su i izvedeni armirano betonski vertikalni i horizontalni serklaži radi povezivanja zidova u jednu monolitnu celinu. Spoljašnji zidovi su sendvič zidovi sačinjeni od giter blokova debljine $25 \mathrm{~cm}$, stiropora ili mineralne vune kao termoizolacija, i opeke (prizemlje) ili bloka debljine $12 \mathrm{~cm}$ (sprat). U prizemlju, pregradni zidovi su od opeke, dok su na spratu zidani blokom debljine $12 \mathrm{~cm}$. Kao element konstrukcije za vertikalnu komunikaciju, izvedeno je drveno jednokrako stepenište.

Tavanska odnosno međuspratna konstrukcija je polumontažnog tipa - Fert konstrukcija debljine $20 \mathrm{~cm}$, dok je podna ploča armirano betonska debljine $20 \mathrm{~cm}(\mathrm{u}$ delu prizemlja na koti 0,00$)$.

Temeljenje objekta izvedeno je na temeljnim trakama, sa dubinom fundiranja $115 \mathrm{~cm}$.

Objekat je pokriven dvovodnim krovom, sa nagibom krovnih ravni 29․ Drvena konstrukcija formirana je kao dvostruka stolica. Upotrebljeni element za pokrivanje je keramički crep.

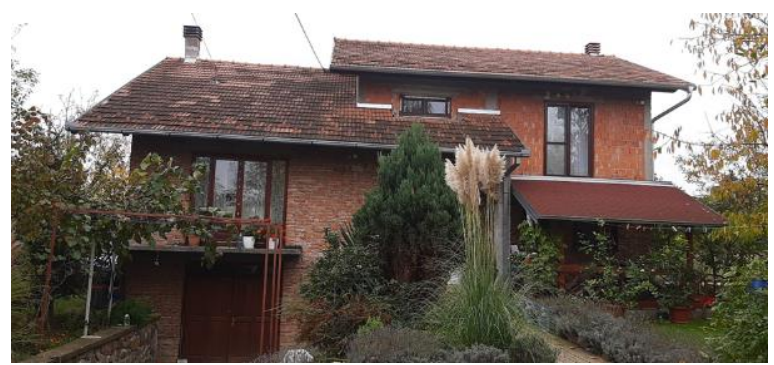

Slika 2. Izgled zapadne fasade objekta

\subsection{Značaj pravilne procene stanja}

Potreba za procenom stanja građevinskih konstrukcija se često sreće u praksi. Pored gradnje novih objekata, jedan od osnovnih ciljeva savremenog građevinarstva je i očuvanje postojećih objekata, bilo da je reč o objektima od velikog značaja, ili o stambenim objektima. Realna procena stanja objekta je u praksi jedan izuzetno kompleksan i složen proces, koji zahteva iskustva i znanja iz različitih oblasti građevinarstva, kao što su tehnologija betona i građevinski materijali, razna destruktivna i nedestruktivna ispitivanja, poznavanje oblasti konstrukterstva i različitih tehnika građenja kao i eksploatacionih uslova [1].

\subsubsection{Analiza oštećenja spoljašnjih površina}

Izlaskom na teren, najpre je vršena provera geometrije objekta, i usklađenost sa projektovanim dimenzijama. Merenjem dostupnih dimenzija po visini i u osnovi, utvrđeno je da odgovaraju onima datim projektom. Nakon toga, prema principima opšte metodologije, izvršen je detaljan vizuelni pregled i snimanje svih defekata i oštećenja, beleženje njihovih lokacija i zapisivanje uočenih karakterističnih detalja [1]. Na ovaj način obrađene su sve dostupne površine zidova, armirano betonskog stuba na ulazu u objekat, nadprozornih i nadvratnih greda i horizontalnih serklaža, kao i konzolne ploče balkona.

Završna obrada fasadnih površina ne postoji - objekat nije omalterisan sa spoljašnje strane, tako da na spoljašnjim površinama objekta uočena su mnoga oštećenja i defekti. Analizom zabeleženih podataka i na osnovu fotografija, primećeno je da se na svim površinama fasade uočavaju isti defekti i oštećenja. Oštećenje koje je registrovano najveći broj puta jesu prsline i pukotine u opeci.

Najmanje ugrožena je južna fasada, gde je karakteristična pojava tzv. kokica u opeci na nekoliko mesta, što je i jedno oštećenje uočeno u elementima za zidanje na toj strani objekta. Najviše nepravilnosti uočeno je na zapadnoj fasadi gde je oštećenje koje je od najvećeg značaja pukotina kroz maltersku spojnicu.

Pregledom dostupnih površina armirano betonskih elemenata, jasno je da radovima na ugrađivanju betona nije posvećena dovoljna pažnja budući da se na gotovo svim elementima primećuju zone segregacije koje su posledica nedovoljnog kompaktiranja betona, kao i veliki broj mesta na kojima je vidljiva armatura, negde i čitavom dužinom šipke, iz čega se može zaključiti da nije izveden dovoljan zaštitni sloj betona.

Ovakva situacija vodi ka koroziji ugrađene armature što izaziva ljuskanje i raslojavanje betona koje je takođe uočeno na više mesta. 


\subsubsection{Analiza oštećenja unutrašnjih površina}

Kada su u pitanju unutrašnje površine, od interesa je bio pregled gornje površine tavanice i krovna konstrukcija izrađena od drveta.

Prilikom obilaska tavanskog prostora, izvršen je i pregled gornje površine tavanice. U pitanju je Fert tavanica, debljine $20 \mathrm{~cm}$. Na predmetnoj ploči registrovana je jedna prslina koja se pruža od blizine obodnog zida pa sve do gotovo polovine ploče, u središnjem delu.

Vizuelnim pregledom krovne konstrukcije, uočene su pukotine u drvenoj građi na pojedinim mestima za koje je utvrđeno da ne utiču bitnije na elemente krova. Osim toga, na predmetnoj drvenoj građi nisu zabeleženi tragovi biološke deterioracije misleći na gljivice, bakterije, insekte, crve i termite.

Mestimično su registrovane greške građe drveta $u$ vidu prisutnih čvorova kao slučajni defekti u vidu posledica dozvoljenih prirodnih grešaka drveta [2].

\subsection{Zaključak o stanju objekta}

Nosivost, stabilnost i upotrebljivost nisu ugroženi budući da nisu zabeležene nepravilnosti koje bi do toga mogle dovesti (iako bi vidljivu armaturu bilo poželjno očistiti i naneti adekvatan zaštitni sloj betona kako ne bi došlo do značajnijeg propadanja AB elemenata). Trajnost spoljašnjih zidova nije ugrožena, ali u nekoj meri može biti smanjena zbog pukotina $\mathrm{u}$ opeci kroz koje atmosferilije mogu prodirati u unutrašnji deo zida.

Takođe, pomenute činjenice vezane za trajnost, idu u prilog tome da je kao element za zidanje spoljašnjeg dela zida upotrebljena obična puna opeka koja je sama po sebi lošijeg kvaliteta, sa većim procentom upijanja vode pa samim tim i većom osetljivošću na dejstvo mraza, sa prisutnim krečnim uključcima, prslinama, odvaljenih ivica, kao posledica uslova kvaliteta koji se propisuju za ovakve elemente. Kao takva, obična puna opeka nije predviđena da se upotrebljava bez zaštitnog sloja u vidu maltera, direktno izložena dejstvu atmosferilija.

\section{PRORAČUN ENERGETSKE EFIKASNOSTI TRENUTNOG STANJA OBJEKTA}

Elaborat energetske efikasnosti, odnosno proračun energetske efikasnosti, izrađen je prema važećem Pravilniku o energetskoj efikasnosti zgrada, „Službeni glasnik RS“ br. 61/2011.

Definisano je 9 netransparentnih pozicija, od toga 5 spoljašnjih zidova, 2 poda na tlu, 1 krovna ploča i 1 ploča iznad negrejanog prostora. Transparentnih pozicija ima ukupno 11 i to 7 prozora i 4 vrata. Odrađen je proračun građevinske fizike za svaku od pozicija (prolaz temperature, difuzija vodene pare, proračun letnje stabilnosti). U Tabeli 1 su date vrednosti koeficijenta prolaza toplote $\mathrm{U}$, po pozicijama, i podatak o ispunjavaju uslova o najvećem dozvoljenom koeficijentu $U$.

Nakon toga, izačunati su transmisioni gubici kroz transparentne i netransparentne površine, ventilacioni i linijski gubici, kao i dobici od sunčevog zračenja i unutrašnjih izvora. Ustanovljeno da su gubici energije kroz netransparentne elemente $(11,345)$ i ventilacioni gubici $(4,434)$, najveće vrednosti (Slika 3).
Tabela 1. Vrednosti koeficijenta prolaza toplote Ui

\begin{tabular}{|c|c|c|c|c|}
\hline ELEMENT & POZICIAA & $\mathrm{U}(\mathrm{W} / \mathrm{m} 2 \mathrm{~K})$ & Umax (W/m2K) & ZADOVOLENO \\
\hline \multirow{5}{*}{ SPOUAŠNJI ZIDOVI } & SZ1 & 0.432 & 0.4 & $\mathrm{NE}$ \\
\hline & $5 Z 2$ & 0.508 & 0.4 & $\mathrm{NE}$ \\
\hline & $S Z 3$ & 0.498 & 0.4 & $\mathrm{NE}$ \\
\hline & $5 Z 4$ & 0.43 & 0.4 & $\mathrm{NE}$ \\
\hline & 525 & 0.505 & 0.4 & $\mathrm{NE}$ \\
\hline \multirow{4}{*}{$\begin{array}{l}\text { MEDUSPRATNE } \\
\text { KONSTRUKCIJE }\end{array}$} & PT1 & 0.816 & 0.4 & $\mathrm{NE}$ \\
\hline & PT2 & 0.917 & 0.4 & $\mathrm{NE}$ \\
\hline & MKNK & 2.473 & 0.4 & $\mathrm{NE}$ \\
\hline & MKNP & 0.772 & 0.4 & $\mathrm{NE}$ \\
\hline \multirow{7}{*}{ PROZORI } & PR1 & 3.04 & 1.5 & $\mathrm{NE}$ \\
\hline & PR2 & 3.03 & 1.5 & $\mathrm{NE}$ \\
\hline & PR3 & 3.06 & 1.5 & $\mathrm{NE}$ \\
\hline & PR4 & 3.02 & 1.5 & $\mathrm{NE}$ \\
\hline & PR5 & 3.05 & 1.5 & $\mathrm{NE}$ \\
\hline & PR6 & 3.02 & 1.5 & $\mathrm{NE}$ \\
\hline & PR7 & 3.05 & 1.5 & $\mathrm{NE}$ \\
\hline \multirow{4}{*}{ VRATA } & VR1 & 2.4 & 1.5 & $\mathrm{NE}$ \\
\hline & VR2 & 3.03 & 1.5 & $\mathrm{NE}$ \\
\hline & VR3 & 2.4 & 1.5 & $\mathrm{NE}$ \\
\hline & VR4 & 3.03 & 1.5 & $\mathrm{NE}$ \\
\hline
\end{tabular}

\section{PODACI O GUBICIMA TOPLOTE}

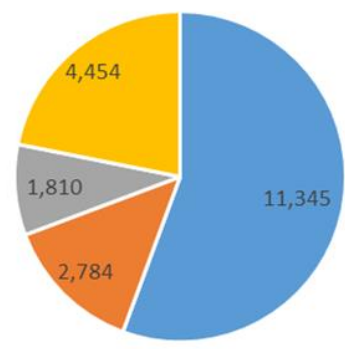

$$
\begin{aligned}
& \text { = Transmisioni gubici kroz netransparentne površine } \\
& \text { = Transmisioni gubici kroz transparentne površine } \\
& \text { = Linijski gubici } \\
& \text { = Ventilacioni gubici }
\end{aligned}
$$

Slika 3. Energetski gubici na postojećem objektu

Na kraju je izračunata ukupna potrebna energija za grejanje za sistem koji radi bez prekida, kao i po mesecima.

$\mathrm{Na}$ osnovu ovoga, zgrada se svrstava u energetski razred D.

\section{MERE ENERGETSKE SANACIJE I PRORAČUN ENERGETSKE EFIKASNOSTI SANIRANOG STANJA OBJEKTA}

Sanacija objekta se sprovodi prema najvećim gubicima. U ovom slučaju sanirani su svi spoljni zidovi, tavanica kao i ploča iznad negrejanog prostora podruma, i urađena je zamena svih prozora na objektu. Osmišljena je i zastakljena terasa na južnoj fasadi u cilju njenog otvaranja i povećavanja prodora sunčeve svetlosti i toplote.

Usvojeno rešenje podrazumeva nanošenje termoizolacionog maltera na bazi perlita na fasadne zidove u sloju debljine $2 \mathrm{~cm}$ [5]. Osim toga, previđeno je i da se izvrši oblaganje međuspratnih konstrukcija Ytong Multipor pločama potrebne debljine [4], dobijene iz uslova zadovoljenja vrednosti Umax.

Takođe, potrebno sprovesti mere koje se tiču produženja trajnosti, kako bi mere predviđene poboljšanju energetske efikasnosti objekta mogle biti pravilno i kvalitetno 
izvedene - registrovane pukotine i prsline zaseći, zapuniti, postaviti mrežicu i poravnati površinu, uočene ogoljene šipke armature očistiti, naneti odgovarajući zaštitni premaz i izvesti reprofilaciju na tim i drugim mestima gde postoji potreba za takvom vrstom popravke.

Svi transparentni elementi se zamenjuju. Tip stakla upotrebljen u ovom slučaju je dvostruko, niskoemisiono, 4-12-4 mm sa punjenjem od ksenona [3], dok su okviri zadržani drveni budući da je drvo ekološki adekvatan materijal.

Ponovno je sproveden proračun energetske efikasnosti prema važećem Pravilniku o energetskoj efikasnosti zgrada, „Službeni glasnik RS“ br. 61/2011, ali za ove novodefinisane sklopove. Nakon proračuna građevinske fizike i proračuna gubitaka, uviđa se da su predmetne vrednosti znatno smanjene (Slika 4).

\section{PODACI O GUBICIMA TOPLOTE NAKON SANACIJE}

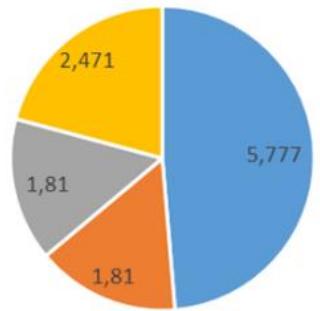

$$
\begin{aligned}
& \text { - Transmisioni gubici kroz netransparentne površine } \\
& \text { = Transmisioni gubici kroz transparentne površine } \\
& \text { " Linijski gubici } \\
& \text { = Ventilacioni gubici }
\end{aligned}
$$

\section{Slika 4. Energetski gubici na saniranom objektu}

Nakon proračuna dobitaka, i potrebne energije za grejanje objekta određen je novi energetski razred objekta - "C".

\section{ZAKLJUČAK}

U praktičnom delu rada izvršena je procena stanja objekta i zaključeno je da nosivost i stabilnost nisu ni najmanje ugrožene, dok je trajnost narušena $u$ manjoj meri. Pristupljeno je proračunu gde je objekat kategorizovan $\mathrm{u}$ energetski razred „D“. Kako bi se u isto vreme povećala trajnost objekta, ali i smanjila količina energije potrebne za zagrevanje objekta popravljene su karakteristike oderđenih elemenata objekta.

Spolji zidovi su obavijeni kvalitetnim termoizolacionim malterom visokih performansi, u proračunom dobijenoj debljini. Na mestima gde je još bila potrebna izolacija, postavljene su Ytong Multipor ploče, takođe veoma dobrih karakteristika, dok su na prozorima zamenjena stakla, upotrebljavajući ona mnogo sa boljim izolacionim karakteristikama.

Nakon ponovljenog proračuna energetske efikasnosti na saniranom objektu, on je svrstan u energetski razred „C““. Budući da se energetska sanacija jednog objekta smatra uspešnom ako je ostvareno povećanje energetskog razreda za jedan, ova sanacija se ubraja u uspešne. Na Slici 5 prikazana je potrebna količina energije za zagrevanje postojećeg i saniranog objekta, dato po mesecima.
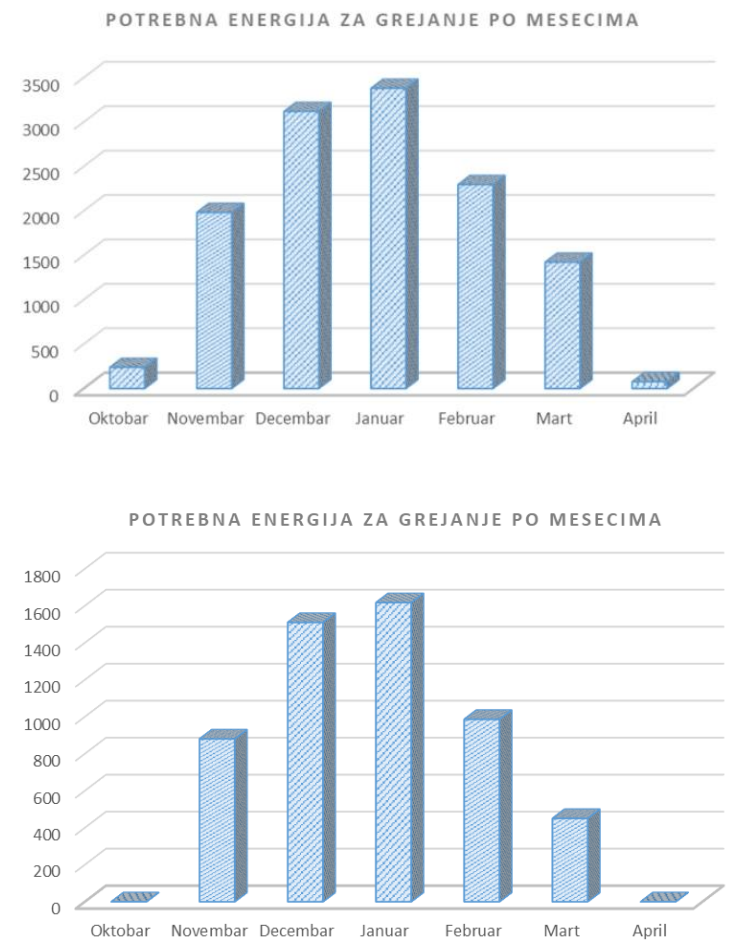

Slika 5. Potrebna energija za zagrevanje postojećeg $i$ energetski saniranog objekta

\section{LITERATURA}

[1]Malešev M., Radonjanin V.: „Trajnost i procena stanja betonskih konstrukcija“, Skripta sa predavanja, Fakultet tehničkih nauka, Novi Sad

[2]Kočetov Mišulić T.: „Oštećenja i sanacija drvenih konstrukcija“, Skripta sa predavanja, Fakultet tehničkih nauka, Novi Sad

[3]Inženjerska komora Srbije, „Pravilnik o energetskoj efikasnosti zgrada „Službeni glasnik RS“ broj 61/2011“,

Beograd

[4] https://www.ytong.rs/

[5] https://www.termika.rs/

[6]Vukadinović A. i dr.: „Mere za poboljšanje energetske efikasnosti zgrada“, Stručni rad

\section{Kratka biografija:}

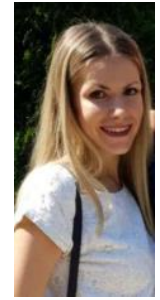

Jovana Kronić rođena je u Novom Sadu 1995. god. Master rad na Fakultetu tehničkih nauka iz oblasti Građevinarstvo - Konstrukcije, procena stanja i sanacija betonskih konstrukcija odbranila je 2020.god.

kontakt: jovana.kronic@gmail.com 